\title{
Endovascular Management of Spinal Dural Arteriovenous Fistulas
}

\author{
Nitin Agarwal ${ }^{1,2}$ David R. Hansberry ${ }^{3}$ Ahmed Meleis ${ }^{2}$ Bryan A. Lieber ${ }^{4}$ Chirag D. Gandhi ${ }^{2,3}$ \\ Charles J. Prestigiacomo $2,5,6$
}

${ }^{1}$ Department of Neurological Surgery, University of Pittsburgh

Address for correspondence Charles J. Prestigiacomo, MD, Medical Center, Pittsburgh, Pennsylvania, United States

2 Department of Neurological Surgery, Rutgers New Jersey Medical

School, Newark, New Jersey, United States

${ }^{3}$ Department of Radiology, Thomas Jefferson University Hospitals, Philadelphia, Pennsylvania, United States

${ }^{4}$ Department of Neurological Surgery, University of Arkansas for Medical Sciences, Little Rock, Arkansas, United States

${ }^{5}$ Department of Radiology, Rutgers New Jersey Medical School, Newark, New Jersey, United States

${ }^{6}$ Department of Neurology and Neuroscience, Rutgers New Jersey Medical School, Newark, New Jersey, United States Department of Neurological Surgery, University of Pittsburgh Medical Center, Pittsburgh, PA, United States (e-mail: agarwaln@upmc.edu).

J Neurol Surg A 2016;77:523-526.

\begin{abstract}
Keywords

- spinal dural arteriovenous fistula

- endovascular

- liquid embolization

- management

Spinal vascular malformations, although rare, cause devastating disease. These malformations are commonly categorized as follows: spinal arteriovenous malformations (AVMs), dural arteriovenous fistulas (DAVFs), spinal hemangiomas, cavernous angiomas, and aneurysms. Spinal DAVFs (SDAVFs), or type 1 spinal AVMs, occur most frequently, representing $\sim 60$ to $80 \%$ of vascular malformations of the spinal cord. While previously microsurgical treatment was considered the gold standard in the treatment of SDAVFs, recent advancements in technology-advancements of magnetic resonance imaging as a screening examination, contrast-enhanced magnetic resonance angiography, multidetector computed tomography as preangiographic evaluations, digital subtraction angiography, diagnostic catheters, and embolization materials-have made endovascular treatment a possible option. We review the treatment of SDAVFs, primarily discussing the endovascular management of these lesions.
\end{abstract}

\section{Introduction}

Spinal vascular malformations, albeit rare, cause devastating disease. These malformations are commonly categorized as follows: spinal arteriovenous malformations (AVMs), dural arteriovenous fistulas (DAVFs), spinal hemangiomas, cavernous angiomas, and aneurysms. Spinal dural arteriovenous fistulas, or type 1 spinal AVMs, occur most frequently, representing $\sim 60$ to $80 \%$ of vascular malformations of the spinal cord. ${ }^{1-4}$ One retrospective series estimated between 5 and 10 million per year in the general population. ${ }^{5}$ Male patients and those patients in their sixth or seventh decade of life appear to be at greater risk for developing a spinal dural arteriove-

received

May 2, 2015

accepted after revision

September 30, 2015

published online

January 25, 2016

nous fistula (SDAVF) ${ }^{6-9}$ Reportedly, $<1 \%$ of patients with DAVFs are $<30$ years of age. ${ }^{5}$ Conventionally, open surgical ligation of spinal DAVFs was the primary intervention, ${ }^{1,4,10,11}$ However, more recently, health care advances have opened the door for endovascular treatment modalities. As such, we review the treatment of SDAVFs, primarily discussing the endovascular management of these lesions.

\section{Indications and Contradictions}

Advancements in neuroimaging have improved the detection of SDAVFs, with a reported delay of 12 to 44 months between the

(c) 2016 Georg Thieme Verlag KG Stuttgart · New York
DOI http://dx.doi.org/ 10.1055/s-0035-1570002. ISSN 2193-6315. 
onset of symptoms and diagnosis. ${ }^{12,13}$ Despite the advancement of magnetic resonance (MR) imaging from a $0.5 \mathrm{~T}$ to a $1.5 / 3.0-\mathrm{T}$ magnet, it may not lead to an early diagnosis of the lesions. Even today, it takes a year or more to make a diagnosis of DAVFs. Moreover, whether or not earlier detection enhances the efficacy of surgical and endovascular management options remains controversial. ${ }^{14-16}$ Patients often present with motor weakness, gait disturbances, sensory disturbances, and bowel, bladder, or sexual dysfunction. 2,11,14,17,18 Although some reports have cited a punctuated stepwise course of disease, typically SDAVFs demonstrate a gradual progression in the severity of symptoms. ${ }^{12,19}$ Following the recognition of clinical symptoms, ${ }^{10}$ imaging is utilized to confirm a positive diagnosis of SDAVFs. Selective angiography is considered the gold standard method of diagnosis. The advancements of digital substraction angiography (DSA) including three-dimensional images and diagnostic catheters enable a more detailed visualization of the fistulas. Still magnetic resonance (MR) imaging, magnetic resonance angiography (MRA), or computed tomography (CT) myelography may also be used. ${ }^{1}$

Indications for spinal DAVFs on MR imaging include increased signal intensity along the center of the spinal cord on T2weighted scans. $^{3,20,21}$ Spinal dural arteriovenous fistulas are typically observed in the thoracolumbar regions, whereby hyperintensity commonly spans five to seven vertebral levels on imaging. ${ }^{7}$ MR imaging has also demonstrated that flow voids, thought to be representing blood flow within dilated medullary veins, are suggestive of SDAVFs in $35 \%$ of patients. ${ }^{3,6,20,22}$ In a study utilizing MRA to diagnose SDAVFs, $100 \%$ of patients demonstrated abnormal intradural vessels. ${ }^{21}$ The introduction of contrast-enhanced MRA and multidetector CT may lead to successful localization of the fistulas before DSA.
Contraindications to the endovascular management of SDAVFs depend in part on the associated vasculature. In particular, feeder vessels for DAVFs should be assessed including the ascending cervical, deep cervical, intercostal, lumbar, sacral, and internal iliac arteries. ${ }^{12,23}$ Embolization of arterial feeders is contraindicated due to the elevated risk of spinal cord ischemia and infarction; this caveat is especially true for involved arteries that supply the anterior spinal artery, such as the anterior segmental medullary artery. 1,16,24

\section{Surgical Technique}

Patients scheduled for endovascular management are placed in a position consistent with that for conventional angiography. In the supine position, patients are intubated and placed under general anesthesia. An incision is made in the skin to expose the femoral artery in the right groin. Standing on the right side of the patient, the surgeon threads a catheter through the small incision up the femoral artery to the site of the SDAVF (-Fig. 1A, B). Embolic agents are injected via the catheter, thereby reducing blood flow to abnormal vessels.

Whereas microsurgical treatment was previously considered the gold standard in the treatment of SDAVFs, recent advancements in technology have made endovascular treatment a possible option. However, regardless of treatment modality, positive postoperative function is highly related to preoperative presentation and the timing of endovascular or microsurgical treatment. ${ }^{25}$ The less invasive endovascular treatment can be performed following spinal angiography and provides significant benefits to patients.

Endovascular treatments frequently use liquid embolization materials as well as particle embolization. Particle embolization
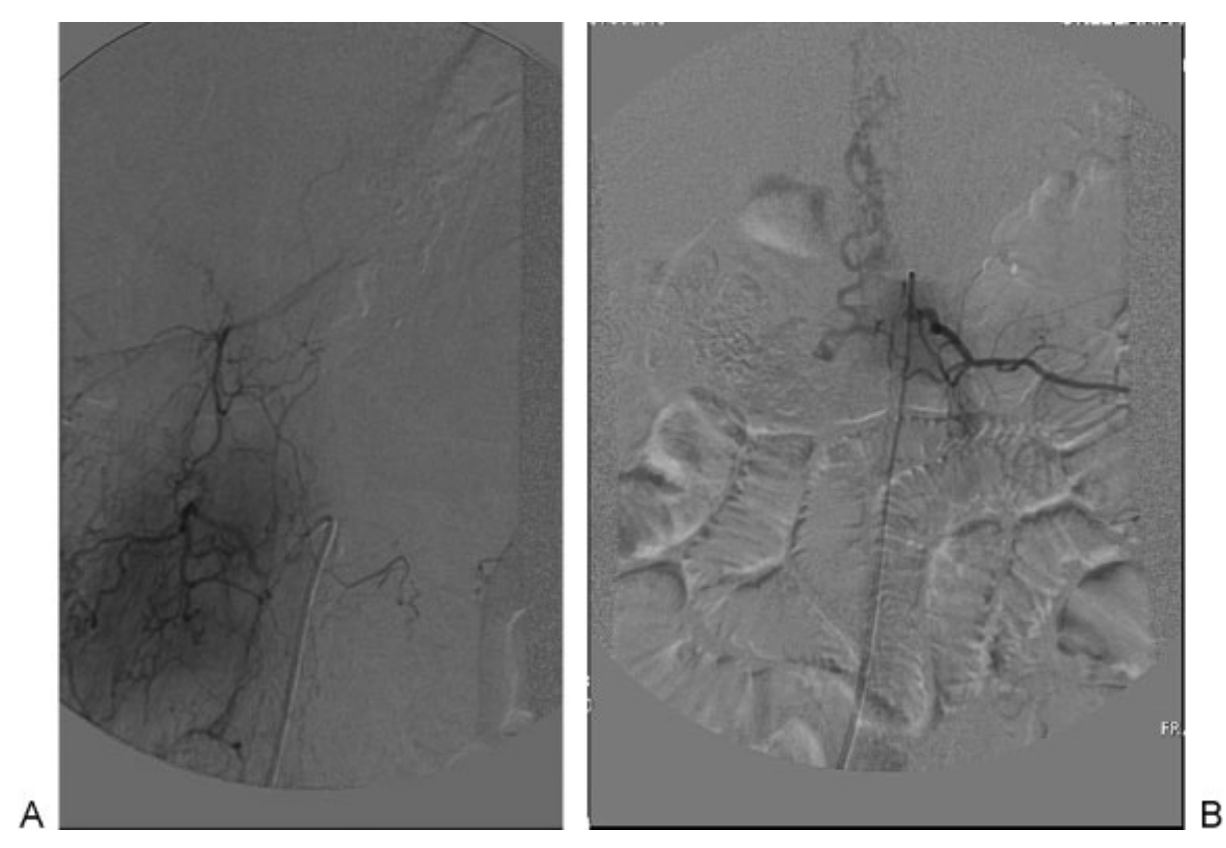

Fig. 1 Type I spinal arterial venous malformation. (A) The right L3 spinal segmental artery bears a fistulous connection supplying a dural arteriovenous fistula with retrograde flow along the route to the pial venous plexus. The venous drainage is reversed in that vein. (B) A large dural arterial venous fistula at the right L1 pedicle, with an obvious fistulous site at the dural sleeve of the nerve root. Drainage was predominantly into the spinal canal and superiorly with delay in transit time, consistent with venous hypertension. 
materials, like polyvinyl alcohol, Gelfoam, and Embosphere, are used less commonly because of frequent recanalization with particles usually lodging in the arterial side of the arteriovenous shunt, thereby never reaching the venous side. ${ }^{26-28}$ Liquid embolization includes materials such as $\mathrm{N}$-butylcyanoacrylate (NBCA) and Onyx (EV3, Irvine, California, United States). ${ }^{29,30}$

NBCA is an acrylic polymer that polymerizes upon interaction with an ionic medium like blood. It is known as glue because it adheres to biological surfaces. ${ }^{1}$ The advancement of embolization materials (particles to glue) decreases the recurrence rate of the fistulas. To improve visualization during endovascular treatment, NBCA is mixed with ethiodized oil to make it radiopaque. A newer liquid polymer, Onyx, is composed of ethylene-vinyl alcohol suspended in dimethyl sulfoxide. ${ }^{29}$ A key advantage of Onyx is its ability to be delivered slowly and its high penetration due to a lack of adherence to biological surfaces. Prior to endovascular delivery of Onyx, the solution needs to be agitated for 20 minutes and the microcatheter primed with dimethyl sulfoxide. The liquid solution is delivered to the occlusion of the proximal draining vein, allowing the liquid polymer to travel past the fistula until the fistula is completely occluded. ${ }^{25,31}$ The objective of embolization is to occlude the fistula completely as well as the proximal draining vein at the site of the fistulization. ${ }^{25}$ After endovascular treatment, a spinal angiography can evaluate the efficacy of the embolization including an assessment of the SDAVF and local vasculature.

\section{Potential Alternative Approaches}

Although endovascular treatment can be desirable, it can be contraindicated in specific situations. In fact, surgical intervention is often performed and has proven extremely effective with success rates $\sim 98 \%$ ( $\mathbf{- \text { Fig. }}$ 2A, B). ${ }^{9}$ Excellent obliteration rates with low morbidity have been reported for surgical division, while very variable, and at times, inferior results have been reported on long-term follow-up after endovascular therapy. ${ }^{32-35}$ Furthermore, the use of intraoperative microvascular Doppler monitoring and indocyanine green videoangiography enable immediate assessment of treatment efficacy. ${ }^{36,37}$ As such, alternative approaches should be considered when endovascular treatment is contraindicated in patients, such as those who have a DAVF that supplies both the segmental artery and the anterior or posterior spinal artery because of an increased risk of spinal cord ischemia with endovascular treatment. ${ }^{25}$ Additionally, when embolization fails, surgical treatment may be required. For example, in patients who have recanalization of a SDAVF after embolization, surgical intervention may be necessary. Treatment of SPDVFs, particularly for children, previously showed promise using stereotactic radiosurgery that uses a Gamma Knife. ${ }^{38,39}$

\section{Pitfalls of the Current and Alternative Approaches}

Despite continued technological advances and vigorous clinical training, both endovascular and surgical treatments have limitations. Endovascular treatment has reported success rates from 25 to $90 \%$ in the literature. ${ }^{13,33,40,41}$ Limitations with the

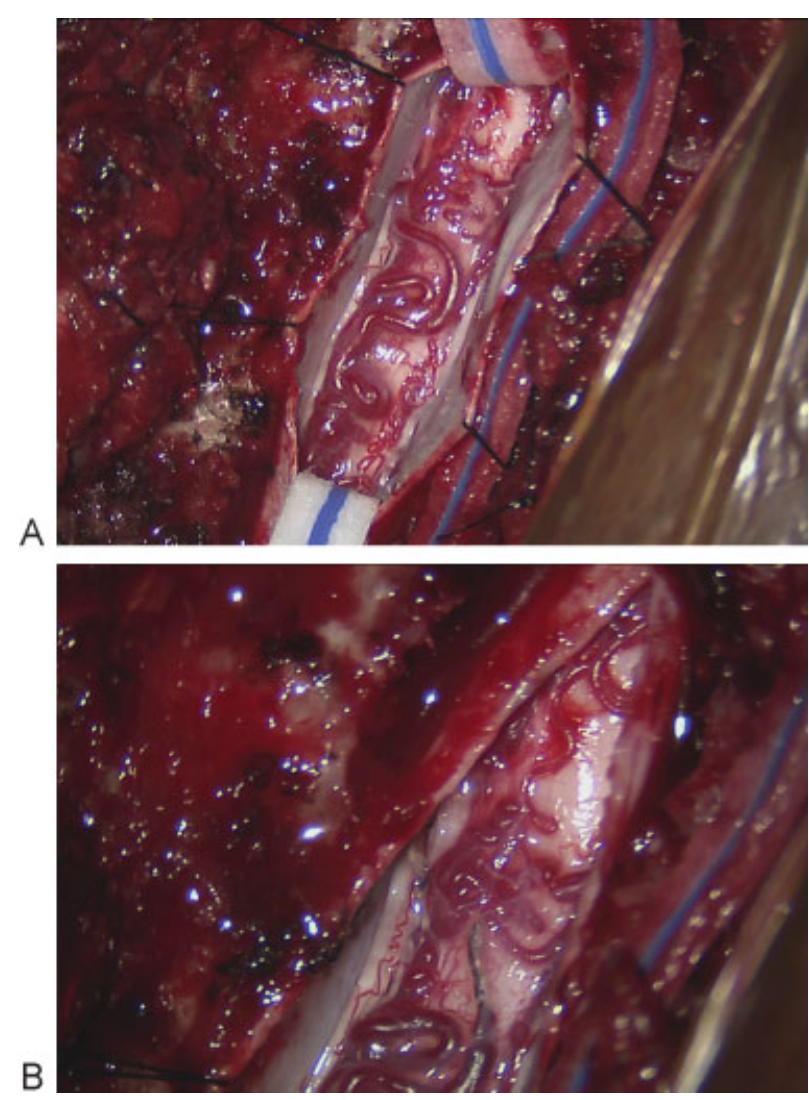

Fig. 2 Type I spinal arterial venous malformation. (A) Preoperative. (B) Postoperative.

liquid polymer NBCA include the unintentional embolization of the wrong arteries, perhaps due to limitations in microcatheter technology. Likewise, the liquid polymer Onyx also has limitations. For instance, recanalization through collateral circulations does occur, possibly because of insufficient delivery of Onyx. However, too much Onyx is also problematic and may inhibit venous circulation and cause venous hypertension. ${ }^{31}$ Both endovascular and surgical treatment have limited recovery of motor deficits, sensory dysfunction, and bladder dysfunction. ${ }^{13,42}$ However, the most substantial issue is that the initial occlusion rate of DAVFs with endovascular treatment has not yet reached that with open surgery ( $72.2 \%$ vs $96.6 \%$ ). Even more concerning, the recurrence rate of DAVFs after endovascular treatment is still higher than that after open surgery. ${ }^{43}$ Further studies are required to assess the efficacy of endovascular treatment compared with open surgical intervention.

\section{References}

1 Sivakumar W, Zada G, Yashar P, Giannotta SL, Teitelbaum G, Larsen DW. Endovascular management of spinal dural arteriovenous fistulas. A review. Neurosurg Focus 2009;26(5):E15

2 Aminoff MJ, Logue V. Clinical features of spinal vascular malformations. Brain 1974;97(1):197-210

3 Gilbertson JR, Miller GM, Goldman MS, Marsh WR. Spinal dural arteriovenous fistulas: MR and myelographic findings. AJNR Am J Neuroradiol 1995;16(10):2049-2057 
4 Oldfield EH, Doppman JL. Spinal arteriovenous malformations. Clin Neurosurg 1988;34:161-183

5 Krings T, Geibprasert S. Spinal dural arteriovenous fistulas. AJNR Am J Neuroradiol 2009;30(4):639-648

6 Caragine LP Jr, Halbach VV, Ng PP, Dowd CF. Vascular myelopathiesvascular malformations of the spinal cord: presentation and endovascular surgical management. Semin Neurol 2002;22(2):123-132

7 Jellema K, Canta LR, Tijssen CC, van Rooij WJ, Koudstaal PJ, van Gijn J. Spinal dural arteriovenous fistulas: clinical features in 80 patients. J Neurol Neurosurg Psychiatry 2003;74(10):1438-1440

8 Van Dijk JM, TerBrugge KG, Willinsky RA, Farb RI, Wallace MC. Multidisciplinary management of spinal dural arteriovenous fistulas: clinical presentation and long-term follow-up in 49 patients. Stroke 2002;33(6):1578-1583

9 Steinmetz MP, Chow MM, Krishnaney AA, et al. Outcome after the treatment of spinal dural arteriovenous fistulae: a contemporary single-institution series and meta-analysis. Neurosurgery 2004; 55(1):77-87; discussion 87-88

10 Oldfield EH, Di Chiro G, Quindlen EA, Rieth KG, Doppman JL. Successful treatment of a group of spinal cord arteriovenous malformations by interruption of dural fistula. J Neurosurg 1983;59(6):1019-1030

11 Kendall BE, Logue V. Spinal epidural angiomatous malformations draining into intrathecal veins. Neuroradiology 1977;13(4):181-189

12 Jellema K, Tijssen CC, van Gijn J. Spinal dural arteriovenous fistulas: a congestive myelopathy that initially mimics a peripheral nerve disorder. Brain 2006;129(Pt 12):3150-3164

13 Narvid J, Hetts SW, Larsen D, et al. Spinal dural arteriovenous fistulae: clinical features and long-term results. Neurosurgery 2008;62(1):159-166; discussion 166-167

14 Song JK, Vinuela F, Gobin YP, et al. Surgical and endovascular treatment of spinal dural arteriovenous fistulas: long-term disability assessment and prognostic factors. J Neurosurg 2001; 94(2, Suppl):199-204

15 Niimi Y, Berenstein A, Setton A, Neophytides A. Embolization of spinal dural arteriovenous fistulae: results and follow-up. Neurosurgery 1997;40(4):675-682; discussion 682-683

16 Aggarwal S, Willinsky R, Montanera W, Terbrugge K, Wallace MC. Superselective angiography of a spinal dural arteriovenous fistula having a common segmental origin with the artery of Adamkiewicz. Neuroradiology 1992;34(4):352-354

17 Aminoff MJ, Logue V. The prognosis of patients with spinal vascular malformations. Brain 1974;97(1):211-218

18 Logue V. Angiomas of the spinal cord: review of the pathogenesis, clinical features, and results of surgery. J Neurol Neurosurg Psychiatry 1979;42(1):1-11

19 Symon L, Kuyama H, Kendall B. Dural arteriovenous malformations of the spine. Clinical features and surgical results in 55 cases. J Neurosurg 1984;60(2):238-247

20 Hurst RW, Grossman RI. Peripheral spinal cord hypointensity on T2-weighted MR images: a reliable imaging sign of venous hypertensive myelopathy. AJNR Am J Neuroradiol 2000;21(4):781-786

21 Bowen BC, Fraser K, Kochan JP, Pattany PM, Green BA, Quencer RM. Spinal dural arteriovenous fistulas: evaluation with MR angiography. AJNR Am J Neuroradiol 1995;16(10):2029-2043

22 Hurst RW, Kenyon LC, Lavi E, Raps EC, Marcotte P. Spinal dural arteriovenous fistula: the pathology of venous hypertensive myelopathy. Neurology 1995;45(7):1309-1313

23 Larsen DW, Halbach VV, Teitelbaum GP, et al. Spinal dural arteriovenous fistulas supplied by branches of the internal iliac arteries. Surg Neurol 1995;43(1):35-40; discussion 40-41

24 Clavier E, Tadie M, Thiebot J, Presles O, Benozio M. Common origin of the arterial blood flow for an arteriovenous medullar fistula and the anterior spinal artery: a case report. Neurosurgery 1986; 18(5):660-663
25 Patsalides A, Santillan A, Knopman J, Tsiouris AJ, Riina HA, Gobin YP. Endovascular management of spinal dural arteriovenous fistulas. J Neurointerv Surg 2011;3(1):80-84

26 Morgan MK, Marsh WR. Management of spinal dural arteriovenous malformations. J Neurosurg 1989;70(6):832-836

27 Nichols DA, Rufenacht DA, Jack CR Jr, Forbes GS. Embolization of spinal dural arteriovenous fistula with polyvinyl alcohol particles: experience in 14 patients. AJNR Am J Neuroradiol 1992;13(3): 933-940

28 Hall WA, Oldfield EH, Doppman JL. Recanalization of spinal arteriovenous malformations following embolization. J Neurosurg 1989;70(5):714-720

29 Saatci I, Geyik S, Yavuz K, Cekirge HS. Endovascular treatment of brain arteriovenous malformations with prolonged intranidal Onyx injection technique: long-term results in 350 consecutive patients with completed endovascular treatment course. J Neurosurg 2011;115(1):78-88

30 Loh Y, Duckwiler GR; Onyx Trial Investigators. A prospective, multicenter, randomized trial of the Onyx liquid embolic system and N-butyl cyanoacrylate embolization of cerebral arteriovenous malformations. Clinical article. J Neurosurg 2010;113(4):733-741

31 van Rooij WJ, Sluzewski M, Beute GN. Brain AVM embolization with Onyx. AJNR Am J Neuroradiol 2007;28(1):172-177; discussion 178

32 Gokhale S, Khan SA, McDonagh DL, Britz G. Comparison of surgical and endovascular approach in management of spinal dural arteriovenous fistulas: A single center experience of 27 patients. Surg Neurol Int 2014;5:7

33 Eskandar EN, Borges LF, Budzik RF Jr, Putman CM, Ogilvy CS. Spinal dural arteriovenous fistulas: experience with endovascular and surgical therapy. J Neurosurg 2002;96(2, Suppl):162-167

34 Andres RH, Barth A, Guzman R, et al. Endovascular and surgical treatment of spinal dural arteriovenous fistulas. Neuroradiology 2008;50(10):869-876

35 Sherif C, Gruber A, Bavinzski G, et al. Long-term outcome of a multidisciplinary concept of spinal dural arteriovenous fistulae treatment. Neuroradiology 2008;50(1):67-74

36 Padovani R, Farneti M, Maida G, Ghadirpour R. Spinal dural arteriovenous fistulas: the use of intraoperative microvascular Doppler monitoring. Br J Neurosurg 2003;17(6):519-524

37 Walsh DC, Zebian B, Tolias CM, Gullan RW. Intraoperative indocyanine green video-angiography as an aid to the microsurgical treatment of spinal vascular malformations. Br J Neurosurg 2014; 28(2):259-266

38 Pollock BE, Flickinger JC, Lunsford LD, Bissonette DJ, Kondziolka D. Hemorrhage risk after stereotactic radiosurgery of cerebral arteriovenous malformations. Neurosurgery 1996;38(4):652-659; discussion 659-661

39 Lunsford LD, Kondziolka D, Flickinger JC, et al. Stereotactic radiosurgery for arteriovenous malformations of the brain. J Neurosurg 1991;75(4):512-524

40 Song JK, Gobin YP, Duckwiler GR, et al. N-butyl 2-cyanoacrylate embolization of spinal dural arteriovenous fistulae. AJNR Am J Neuroradiol 2001;22(1):40-47

41 Jellema K, Sluzewski M, van Rooij WJ, Tijssen CC, Beute GN. Embolization of spinal dural arteriovenous fistulas: importance of occlusion of the draining vein. J Neurosurg Spine 2005;2(5): 580-583

42 Aghakhani N, Parker F, David P, Lasjaunias P, Tadie M. Curable cause of paraplegia: spinal dural arteriovenous fistulae. Stroke 2008;39(10):2756-2759

43 Bakker NA, Uyttenboogaart M, Luijckx GJ, et al. Recurrence rates after surgical or endovascular treatment of spinal dural arteriovenous fistulas: a meta-analysis. Neurosurgery 2015;77(1):137-144; discussion 144 